\title{
Uniaxial Tension of a Filament-wound Composite Tube at Low Temperature
}

\author{
Gy. Szabó ${ }^{1}$, K. Váradi ${ }^{1}$
}

\section{${ }^{1}$ Budapest University of Technology and Economics, Department of Machine and Product Design \\ Bertalan Lajos Street 3, 1111 Budapest, Hungary \\ e-mail: szabo.gyula@gt3.bme.hu}

Abstract: The aim of this article is to model mechanical behavior of a filamentwound, rubber-based composite tube subjected to uniaxial tension at low temperature by test experiments and FE simulations. Uniaxial tensile tests at sub-zero temperature $\left(-40^{\circ} \mathrm{C}\right)$ have been carried out on standard test specimens and on hose pieces. furthermore, a uniaxial tensile test has been performed on a hose piece at room temperature as a reference experiment. Reinforcement layers of the composite tube are modeled as transversely isotropic, whereas elastomer liners are described by 2 parameter Mooney-Rivlin hyperelastic material model. Temperaturedependence of elastic constants of composite layers is attributed to the temperature-dependence of rubber, so uniaxial tensile tests on standard test specimens needed to be carried out for determining material properties of rubber at sub-zero temperature $\left(-40^{\circ} \mathrm{C}\right)$.

Force-displacement results of FE models and experiments of standard test specimen and hose piece show good agreement. Likewise, forcedisplacement curves of reference experiment (carried out at room temperature) and its related FE simulation are in good agreement with each other. Slope of force-displacement curves of hose piece at $-40{ }^{\circ} \mathrm{C}$ is nearly 3.4 times the slope of force-displacement curves of hose piece at room temperature.

Keywords: filament-wound composite tube, rubber-based tube, FE model, uniaxial tension, tensile test, material properties at $-40{ }^{\circ} \mathrm{C}$, sub-zero temperature 


\section{Introduction}

Filament-wound composite tubes are widely used in a number of industrial fields in a wide temperature range, in oil industry, in transportation and aeronautics due to their favorable strength-to-weight and stiffness-to-weight ratio and corrosion resistance. [1]. Filament-winding is the most extensively used manufacturing process because of high volume fraction, low void content and good automation capability [2]. The most commonly encountered operational loads are: internal pressure, uniaxial and biaxial loading, and bending. For balancing internal forces, winding angles of $\pm \Theta$ are typically adopted. Winding angle of a layer is usually set to $\pm 55^{\circ}$, which is the optimal value regarding biaxial loading (combined internal pressure and axial loading) [3,4]. Utilization of rubber as the matrix component gives high flexibility and toughness. One efficient method of acquiring material properties of a composite is performing uniaxial tensile test on a standard test specimen cut from the hose or on a hose piece itself.

Mechanical characterization of composite tubes is most frequently carried out by finite element models [5]. Utilization of formulae of rules of mixture is the most frequent practice for determining elastic constants of a composite. Elastic constants are derived from material properties of the reinforcing yarn and the matrix. In most FE models, plies are modeled as laminates whose elastic constants are generally obtained with the use of the rules of mixtures [6].

In cold environment, modulus of elasticity of matrix increases significantly, while modulus of elasticity of yarns is regarded as constant. Yarn waviness persists, and the resulting load distribution across all yarns becomes less uniform. Therefore, at low temperatures some yarns will share more load than others and fail earlier, resulting in progressive failures of other yarns, thus strength of the composite diminishes [7, 8]. Because the growth in the modulus of elasticity of matrix, during uniaxial tension of the composite tube, the role of the matrix becomes more prominent [9].

Micromechanical behavior of composites also changes with temperature. While at room temperature, matrix cracking has a crucial role in crack initiation; at low temperature, yarn-matrix debonding is much more characteristic because yarnmatrix interface becomes weaker [10].

In this paper, mechanical behavior of a filament-wound composite tube utilized for the passage of air in rail brake systems is investigated. Determination of mechanical properties at low temperature $\left(-40^{\circ} \mathrm{C}\right)$ is presented in detail as well as the comparison of mechanical behavior of the composite tube at low temperature ($40{ }^{\circ} \mathrm{C}$ ) and room temperature. 


\section{Structure and material model of composite tube}

\subsection{Structure of composite tube}

Inner diameter of the composite tube is $28 \mathrm{~mm}$, its outer diameter is $44 \mathrm{~mm}$, the rubber liners are $2.4 \mathrm{~mm}$ thick. There are 4 reinforcement plies consisting of natural yarns and rubber matrix. The material coordinate systems of the plies are cylindrical, the layup is $[+55 /-55 /+55 /-55]\left[{ }^{\circ}\right]$ with respect to the axis of the tube (Figure 1).

Reinforcement plies are surrounded by rubber liners, made of EPDM-EVA copolymer, whose leading role is sealing and protecting reinforcement plies from mechanical impacts.

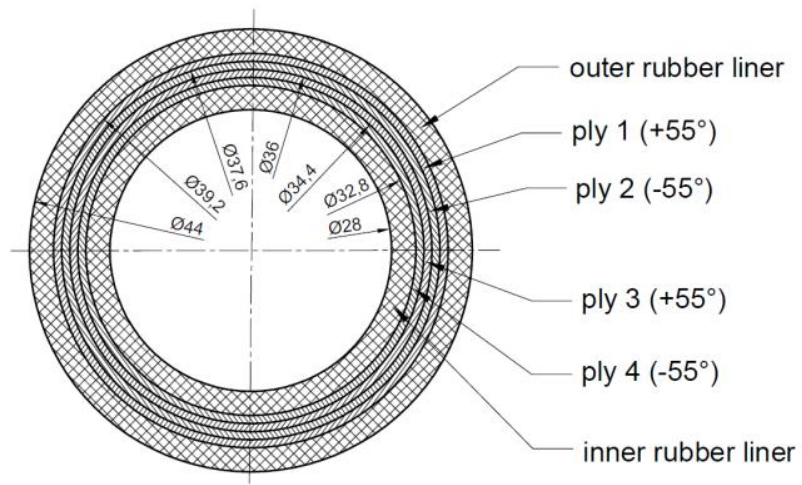

Figure 1. Cross-section of the tube [13]

\subsection{Material model of composite tube}

Material behavior of composites can be described by an anisotropic model in the most general case. Since in this case, the number of independent elastic constants is relatively high (21), obtainment of elastic constants tends to be challenging. Thus generally, the highest order of symmetry is taken into account. Filamentwound composite tubes are most commonly regarded as transversely isotropic because of being uniaxially reinforced, having 3 mutually perpendicular planes of symmetry, the one perpendicular to the yarns is a plane of isotropy $\left(E_{2}=E_{3}\right.$, $\left.\mathrm{G}_{12}=\mathrm{G}_{13}, v_{12}=v_{13}\right)$. Therefore, the number of independent elastic constants can be reduced to $5\left(\mathrm{E}_{1}, \mathrm{E}_{2}, \mathrm{G}_{12}, \mathrm{G}_{23}, v_{12}\right)[11]$. 
Poisson's ratio of the yarn is assumed to be $v_{\mathrm{f}}=0,2$, the Poisson's ratio of the rubber is supposed to be $v_{\mathrm{m}}=0.5$ because the rubber is regarded as incompressible. Elastic constants can be determined based on material parameters modulus of elasticity of fiber $\left(\mathrm{E}_{\mathrm{f}}\right)$, modulus of elasticity of matrix $\left(\mathrm{E}_{\mathrm{m}}\right)$ and fiber volume fraction $\left(\mathrm{V}_{\mathrm{f}}\right)$.

Modulus of elasticity of fiber at $-40^{\circ} \mathrm{C}$ equals modulus of elasticity of fiber at room temperature $\left(\mathrm{E}_{\mathrm{f}}=2961 \mathrm{MPa}\right)$, because its temperature-dependence is negligible. Fiber volume fraction is $\mathrm{V}_{\mathrm{f}}=45 \%$ [13].

Material of the matrix is the same rubber as the liners are made of, because in the course of manufacturing, rubber of rubber liners is vulcanized around yarns. In case of rubber, temperature-dependence is significant [7], therefore for determining elastic constants at $-40^{\circ} \mathrm{C}$, it is inevitable to obtain modulus of elasticity of rubber at $-40{ }^{\circ} \mathrm{C}$. For this reason, standard test specimen has been cut from the outer rubber liner and has been subjected to uniaxial tension. Modulus of elasticity of rubber at $-40{ }^{\circ} \mathrm{C}$ has been determined based on these tensile test results. The calculation method of elastic constants of reinforcement plies is as follows [13]:

Matrix volume fraction is:

$$
\mathrm{V}_{\mathrm{m}}=1-\mathrm{V}_{\mathrm{f}}=1-0.45=0.55
$$

Shear modulus of fiber is:

$$
\mathrm{G}_{\mathrm{f}}=\frac{\mathrm{E}_{\mathrm{f}}}{2 \cdot\left(1+v_{\mathrm{f}}\right)}
$$

Modulus of elasticity in direction 1 is:

$$
E_{1}=E_{f} \cdot V_{f}+E_{m} \cdot V_{m}
$$

Applying the formulae presented in [11] and [12], the modulus of elasticity in directions 2 and 3 and shear moduli are:

$$
\begin{gathered}
E_{2}=E_{3}=\frac{E_{m}}{1-\sqrt{V_{f}} \cdot\left(1-E_{m} / E_{f}\right)} \\
G_{12}=G_{13}=G_{23}=\frac{G_{m}}{1-\sqrt{V_{f}} \cdot\left(1-G_{m} / G_{f}\right)}
\end{gathered}
$$

Since $\mathrm{G}_{\mathrm{f} 12}=\mathrm{G}_{\mathrm{f} 23}$, we can state that $\mathrm{G}_{12}=\mathrm{G}_{23}$.

Poisson's ratios of one ply are [6]:

$$
v_{12}=v_{13}=V_{f} \cdot v_{f}+V_{m} \cdot v_{m}
$$

Contraction in plane 23 is mainly determined by the mechanical behavior of rubber, so 


$$
\mathrm{v}_{23}=\frac{\mathrm{E}_{22}}{2 \cdot \mathrm{G}_{23}}-1
$$

\subsection{Uniaxial tensile test of rubber test specimen, material properties of rubber}

The test specimen has been cut in thickness direction in accordance with standard ASTM D638, thus the thickness of the test specimen is $2.4 \mathrm{~mm}$, equal to the thickness of the outer rubber liner. Lateral section of the rubber test specimen, along with its dimensions, can be viewed in Figure 2. The traction of the test specimen has been conducted to a displacement of $16.5 \mathrm{~mm}$, at which the specimen has ruptured. Force-displacement results have been measured during the tensile test.

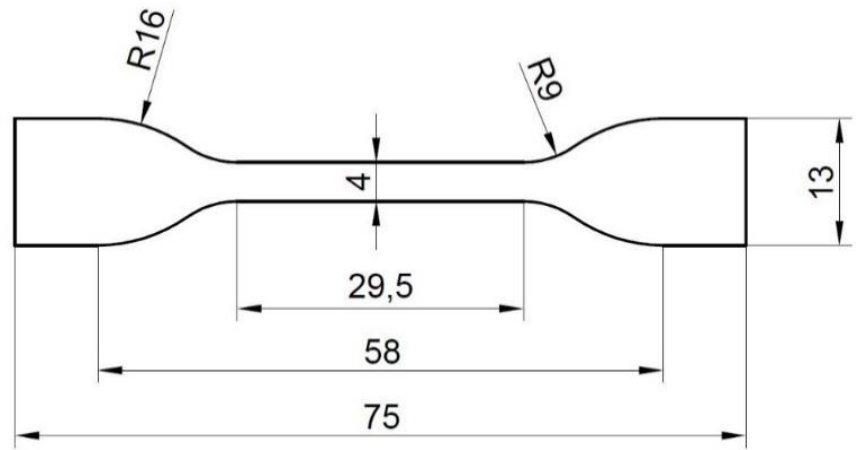

Figure 2. Lateral section of rubber test specimen [13]

Engineering stresses can be calculated based on initial cross-section $\mathrm{A}_{0}=11.2$ $\mathrm{mm}^{2}$ and measured traction force $\mathrm{F}$.

$$
\sigma=\frac{\mathrm{F}}{\mathrm{A}_{0}}
$$

By using distance between grips $\mathrm{l}_{0}=55 \mathrm{~mm}$ and change in length $\Delta \mathrm{l}$, engineering strains can be calculated:

$$
\varepsilon=\frac{\Delta 1}{l_{0}}
$$

Resulting engineering stresses can be viewed as a function of resulting engineering strains in Figure 3. 


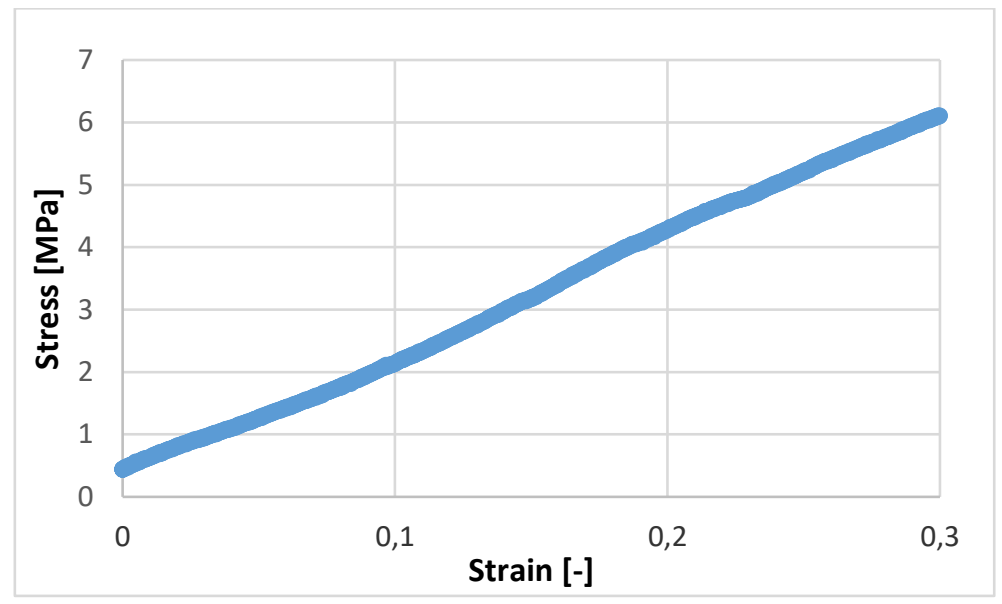

Figure 3. Stress-strain curve of rubber test specimen at $-40 \stackrel{ }{\complement} \mathrm{C}$

Modulus of elasticity of matrix can be determined as follows:

$$
\mathrm{E}_{\mathrm{m}}=\frac{\sigma_{2}-\sigma_{1}}{\varepsilon_{2}-\varepsilon_{1}}=\frac{6,11 \mathrm{MPa}-0,44 \mathrm{MPa}}{0,3-0}=18.91 \mathrm{MPa}
$$

According to data provided by the manufacturer, Shore hardness of the rubber at $-40{ }^{\circ} \mathrm{C}$ is $\mathrm{H}=95 \mathrm{ShA}$.

Shear modulus of rubber can be estimated based on Shore hardness of the rubber [14]:

$$
\mathrm{G}_{\mathrm{r}, \mathrm{est}}=0.086 \cdot 1.045^{\mathrm{H}}=5.63 \mathrm{MPa}
$$

Modulus of elasticity of rubber can be estimated with use of the estimated shear modulus of rubber:

$$
\mathrm{E}_{\mathrm{r}, \mathrm{est}}=2 \cdot\left(1+\mathrm{v}_{\mathrm{r}}\right) \cdot \mathrm{G}_{\mathrm{r}, \text { est }}=16.89 \mathrm{MPa}
$$

The modulus of elasticity of rubber estimated with the use of Eq (12) [14] is approximately equal to that determined based on tensile test experiment. Material properties of reinforcement plies at $-40^{\circ} \mathrm{C}$ with the use of modulus of elasticity of matrix and Eq (3) -(7) are as follows:

$\mathrm{E}_{1}=1345 \mathrm{MPa}, \mathrm{E}_{2}=\mathrm{E}_{3}=57 \mathrm{MPa}, v_{12}=v_{13}=0.364, v_{23}=0.496 ; \mathrm{G}_{12}=\mathrm{G}_{13}=\mathrm{G}_{23}=19 \mathrm{MPa}$. 
Rubber liners are described by a 2 parameter Mooney-Rivlin model (Figure 4), whose parameters have been determined by using the curve fitting feature of Ansys Academic Research [15] on the stress-strain results of rubber test specimen.

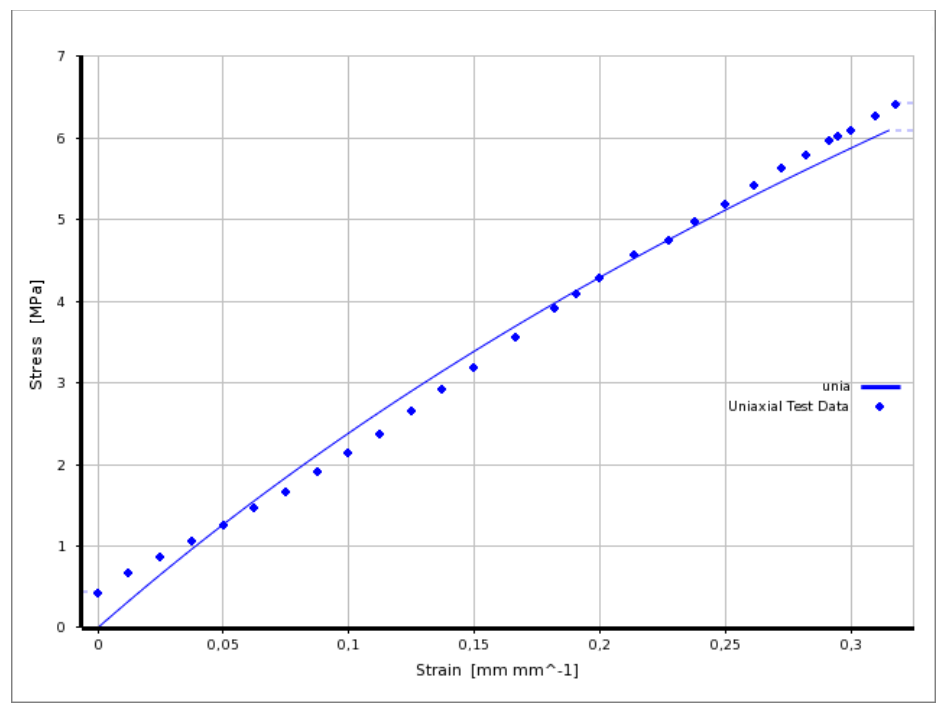

Figure 4. 2 parameter Mooney-Rivlin model fitted to stress-strain results at $-40^{\complement C}$

Mooney-Rivlin parameters of rubber liners are $\mathrm{C}_{10}=2.96 \mathrm{MPa}, \mathrm{C}_{01}=1.53 \mathrm{MPa}$, $\mathrm{D}=0$ [1/MPa].

\section{Uniaxial tension of standard test specimen at $-40{ }^{\circ} \mathrm{C}$}

\subsection{Tensile test experiment of standard test specimen at $-40^{\circ} \mathrm{C}$}

Standard test specimens have been cut from the tube in thickness direction containing both the reinforcement plies and the rubber liners, thus their thickness is $8 \mathrm{~mm}$. Their lateral section is the same as depicted in Figure 2. The tensile test experiment has been performed at $-40{ }^{\circ} \mathrm{C}$ in a climate chamber as depicted in Figure 5. The experiment has begun with a pre-load of $5 \mathrm{~N}$. The test has been executed on a Zwick Z250 tensile testing machine with a tensile speed of $5 \mathrm{~mm} / \mathrm{min}$ to complete rupture at a displacement of $11.7 \mathrm{~mm}$. 


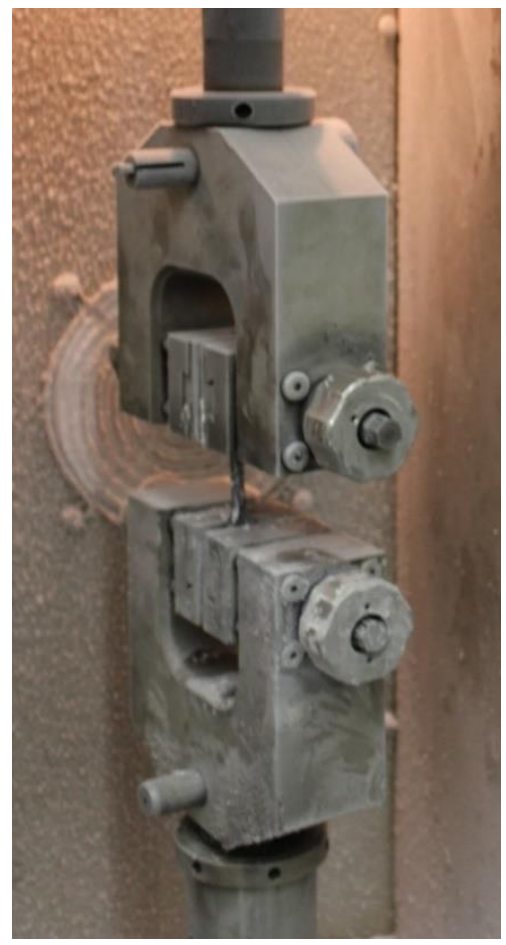

Figure 5. Standard test specimen at $-40^{\circ} \mathrm{C}$, placed in climate chamber

\subsection{FE simulation of uniaxial tension of standard test specimen at $-40{ }^{\circ} \mathrm{C}$}

Geometry of the standard test specimen is the same as that of the test experiment, its lateral section is shown in Figure 2, its thickness is $8 \mathrm{~mm}$. Rigid tensile jaws have been utilized for gripping the test specimen and for executing traction.

The FE mesh comprises second order hexahedral elements to ensure the necessary precision.

\subsubsection{Connections}

Outer and inner rubber liners are in bonded contact with reinforcement plies. The connections of outer rubber liners and the rigid tensile jaws are frictional with a coefficient of friction of $\mu=0.8$ with formulation 'Augmented Lagrange' $[13,16]$. 


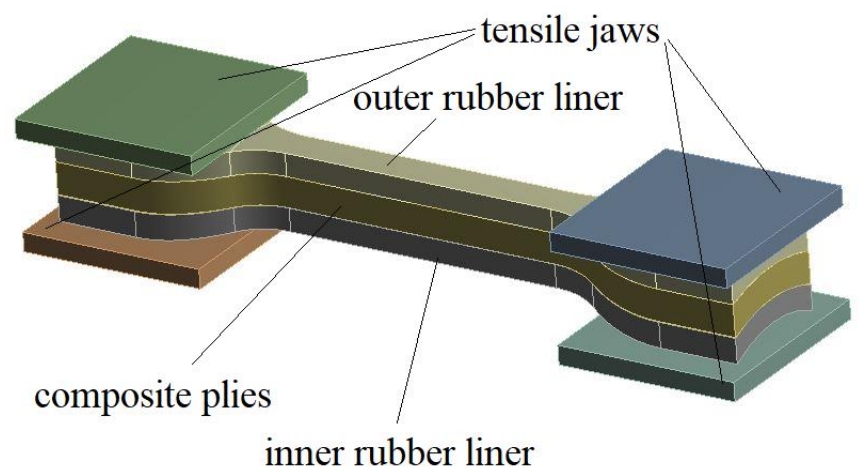

Figure 6. FE model of uniaxial tension of test specimen

\subsubsection{Loads, boundary conditions}

FE simulation is made up of 3 time steps. In the first and the second one, standard test specimen is being fixed between the tensile jaws. In the third time step, tension is being applied to the specimen.

In the first time step, the upper tensile jaw at the right end sinks $-1.8 \mathrm{~mm}$ in $\mathrm{Y}$ direction, whereas the lower tensile jaw is still fixed (Figure 6).

In the second time step, left end of the specimen is being installed. The upper left tensile jaw descends $-1.8 \mathrm{~mm}$ in $\mathrm{Y}$ direction, while the lower right tensile jaw maintains its position.

In the third time step, tensile jaws located at the right end are being displaced $11.6 \mathrm{~mm}$ in positive $\mathrm{X}$ direction.

\subsection{Comparison of experimental and FE simulation results}

Force-displacement results of experiment (conducted at $-40{ }^{-} \mathrm{C}$ ) and FE simulation of standard test specimen are shown in Figure 7. 


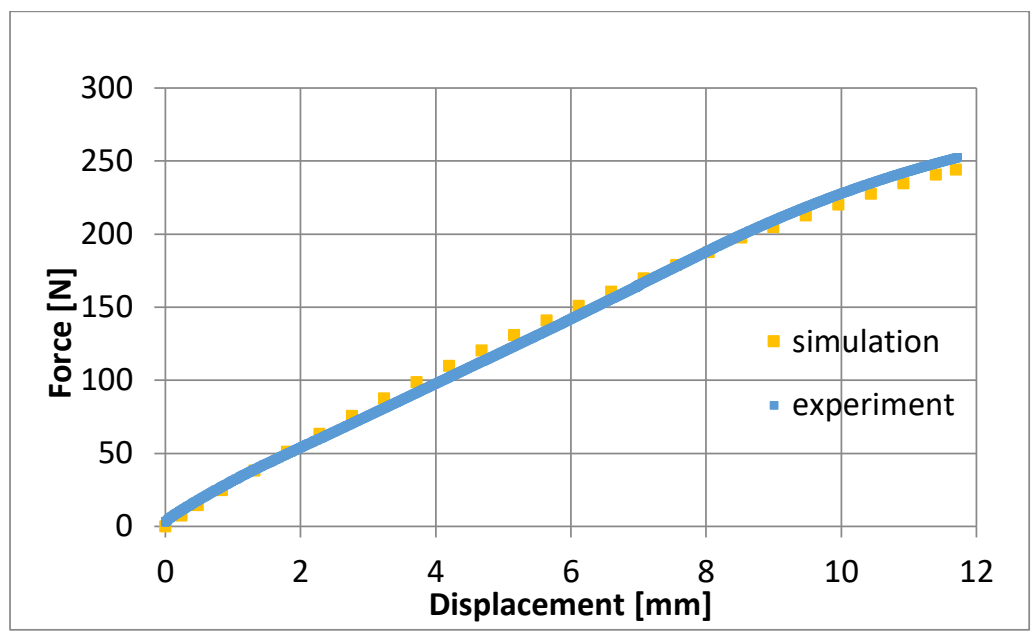

Figure 7. Force displacement curves of standard test specimen, $-40{ }^{\smile} \mathrm{C}$

Force displacement curves of standard test specimen are in acceptable agreement in the entire displacement range investigated.

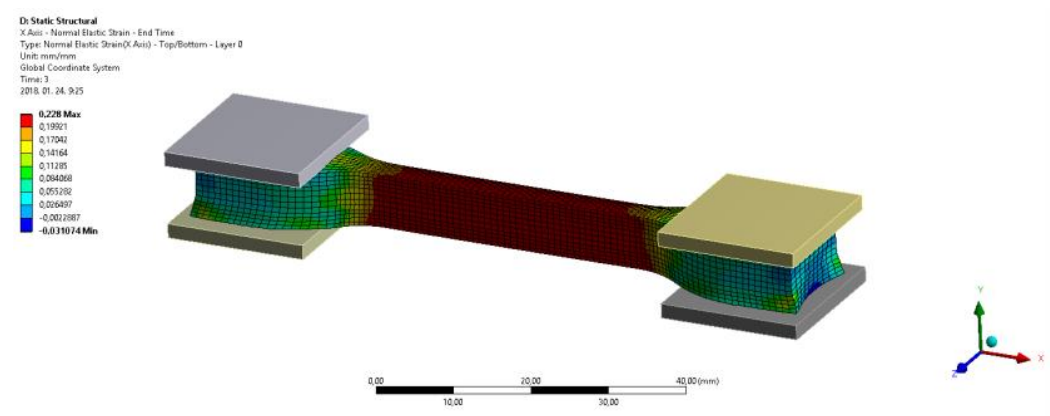

Figure 8. Strain in global X direction at the end of uniaxial tension

At the end of third time step, strain in global $\mathrm{X}$ direction is significant, nearly $\varepsilon_{\mathrm{x}}=0.23$. (Figure 9)

Strain and stress results are hereinafter shown for ply 1 (outermost reinforcement ply) at the end of tension in Figures 9-10 and Figure 11 respectively, mean results are listed for each ply in Table 1 and Table 2. 


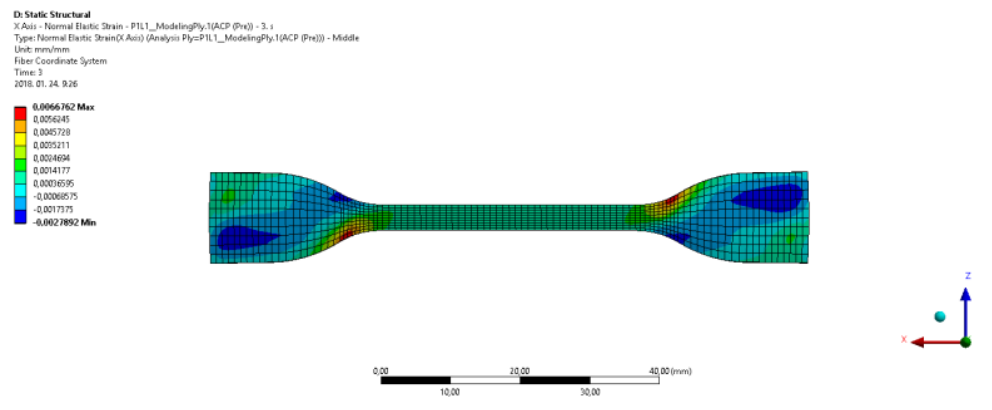

Figure 9. Strain in material direction 1, ply1

Strains in material direction 1 (yarn direction) are noticeably low (Figure 9) due to the high modulus of elasticity in material direction $1, \mathrm{E}_{1}=1345 \mathrm{MPa}$.
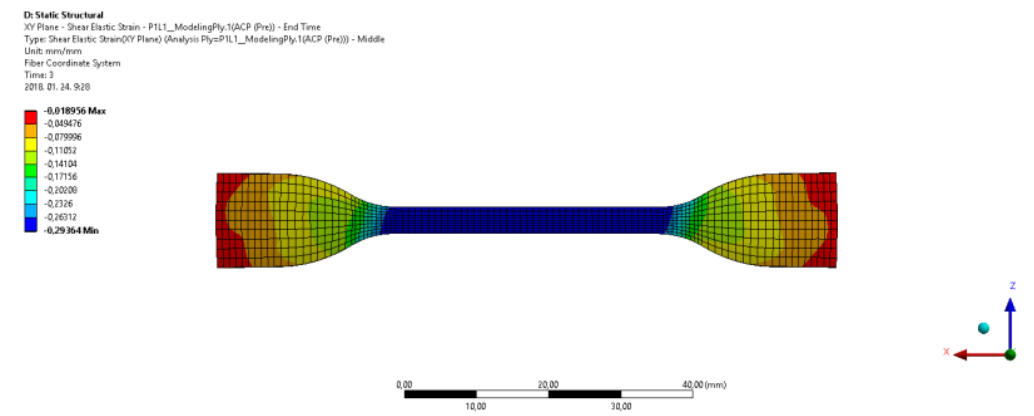

Figure 10. Strain in plane 12, ply1

Figure 10 shows strains in plane 12 in ply1. This component is the most significant in magnitude (Table 1) because the load is off-axis to the yarns, which induces significant shear stresses (Table 2). Because of relatively low shear moduli, high shear strains arise. The absolute value of shear strains is identical for every reinforcement ply, shear strains in adjacent plies have opposite signs due to the symmetric layup. Strains in material direction 2 have the same distribution as shear strains in plane 12. According to Table 1, strain components are distributed equally among plies. 

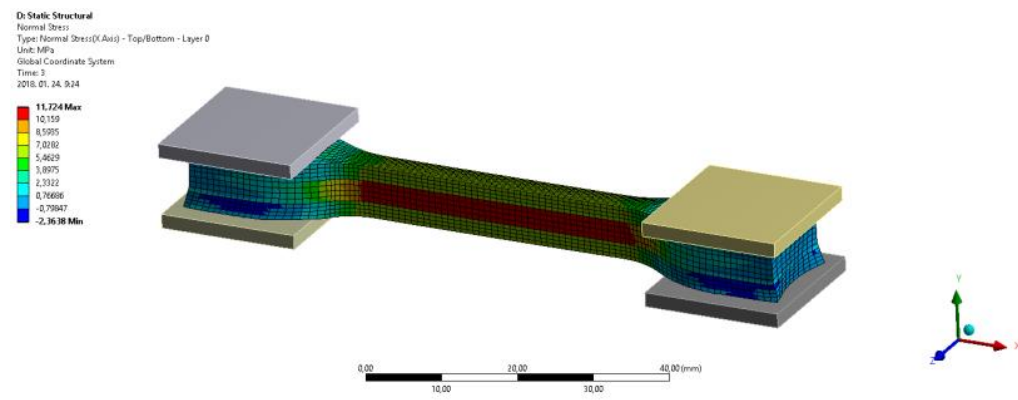

Figure 11. Stress in global X direction at a displacement of $11.7 \mathrm{~mm}$

Highest longitudinal stress values arise in reinforcement layers (Figure 11), whereas approximately half the maximum values arise in rubber liners. This justifies that principally; reinforcement plies bear the load exerted on specimen. Stress components of standard test specimen in material direction 1, material direction 2 and in plane 12 have the same distribution as their strain counterparts.

Table 1. Maximum strains in reinforcement plies in the middle range in the vertical midplane $Y Z$

\begin{tabular}{|c|c|c|c|}
\hline ply no. & $\varepsilon_{1, \max }[-]$ & $\varepsilon_{2, \max }[-]$ & $\boldsymbol{\gamma}_{12, \max }[-]$ \\
\hline 1 & 0.0013 & 0.1181 & -0.2936 \\
\hline 2 & 0.0021 & 0.111 & 0.2989 \\
\hline 3 & 0.0021 & 0.1116 & -0.3014 \\
\hline 4 & 0.0013 & 0.1223 & 0.3003 \\
\hline
\end{tabular}

Table 2. Maximum stresses in reinforcement plies in the middle range in the vertical midplane $Y Z$

\begin{tabular}{|c|c|c|c|c|}
\hline ply no. & $\begin{array}{c}\sigma_{x, \max } \\
{[M P a]}\end{array}$ & $\begin{array}{c}\sigma_{1, \max } \\
{[M P a]}\end{array}$ & $\begin{array}{c}\sigma_{2, \max } \\
{[M P a]}\end{array}$ & $\begin{array}{c}\tau_{12, \max } \\
{[M P a]}\end{array}$ \\
\hline 1 & 11.1 & 4.15 & 6.88 & -5.63 \\
\hline 2 & 11.49 & 5.19 & 6.42 & 5.73 \\
\hline 3 & 11.61 & 5.15 & 6.47 & -5.78 \\
\hline 4 & 11.52 & 4.10 & 7.23 & 5.75 \\
\hline
\end{tabular}




\section{Uniaxial tension of hose piece at $-40^{\circ} \mathrm{C}$}

\subsection{Tensile test experiment of hose piece at $40^{\circ} \mathrm{C}$}

A $150 \mathrm{~mm}$ long hose piece has been subjected to uniaxial tension to a displacement of $35 \mathrm{~mm}$. Cross-section of the hose piece specimen can be seen in Figure 1. Tension has been performed with the help of two steel plugs installed into the hose by pipe clamps and by bonding them to the inner liner of the hose. The hose piece has been put into a climate chamber, whose temperature had been set to $-40^{\circ} \mathrm{C}$ (Figure 12).

Hose piece has been pulled with a tensile speed of $5 \mathrm{~mm} / \mathrm{min}$ and a pre-load of $5 \mathrm{~N}$.

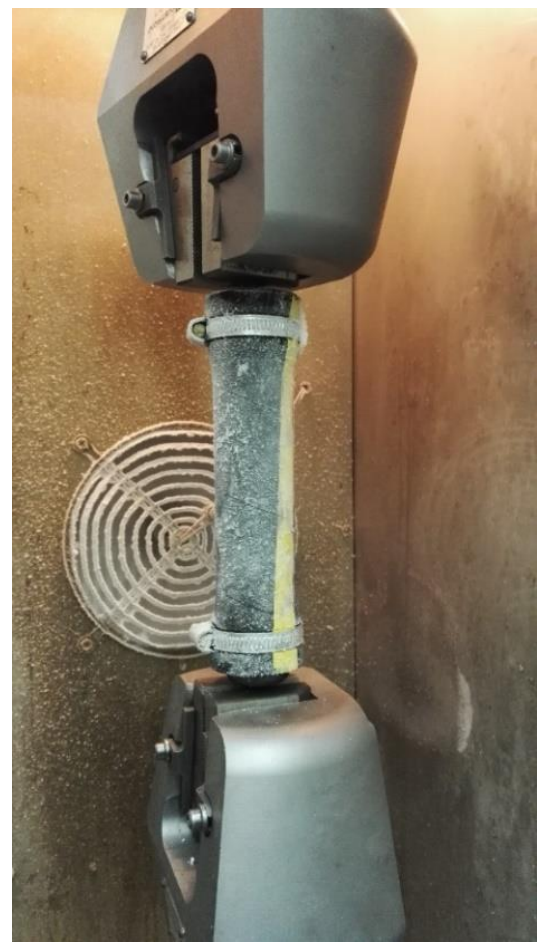

Figure 12. Hose piece specimen at $-40{ }^{\circ} \mathrm{C}$, placed in climate chamber 


\subsection{FE simulation of uniaxial tension of hose piece at $-40^{\circ} \mathrm{C}$}

Geometry of the FE model is identical to that of the experiment. Steel plugs utilized for tension are modeled as rigid bodies.

\subsubsection{Connections}

Reinforcement plies are in bonded contact with outer and inner rubber liners. The rigid plugs are also bonded to the inner lateral surface of the hose.

\subsubsection{Loads, boundary conditions}

In the first time step, pressure of $1.5 \mathrm{MPa}$, representing pipe clamps, is applied to sections of the outer side surface of the hose depicted in Figure 13.

In the second time step, a prescribed displacement of $35 \mathrm{~mm}$ is applied to the right end of the right plug. In the meantime, left end of the left plug is fixed.
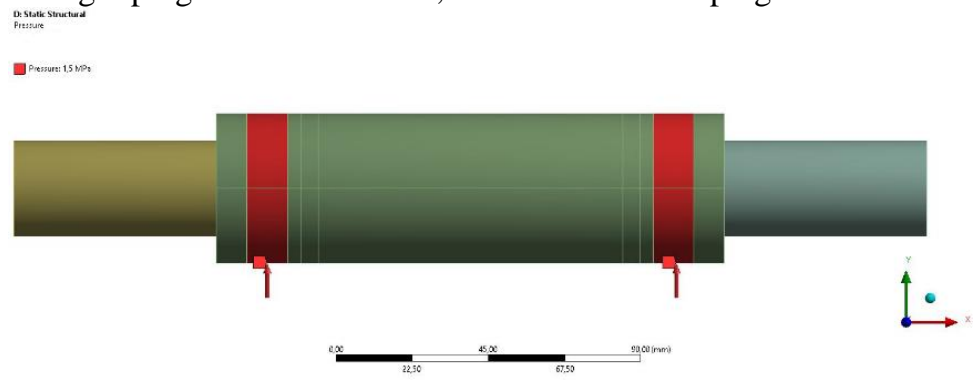

Figure 13. Pressure representing pipe clamps, $1.5 \mathrm{MPa}$

\subsubsection{Material properties}

Material properties of reinforcement plies and rubber liners are described in detail in Chapter 2.2.

\subsection{Comparison of FE simulation and test experiment results}

FE simulation and test experiment results at $-40^{\circ} \mathrm{C}$ (Figure 16) show good agreement in the entire range of uniaxial tension. 


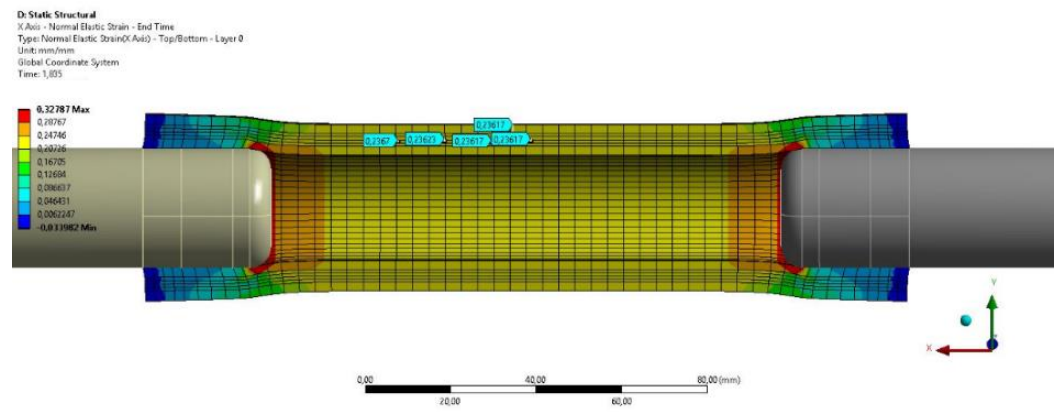

Figure 14. Strain in global X direction

Maximal strain arising in hose piece in the middle range between the steel plugs is 0.23 at a displacement of $30 \mathrm{~mm}$ (Figure 14), which is considered significant.

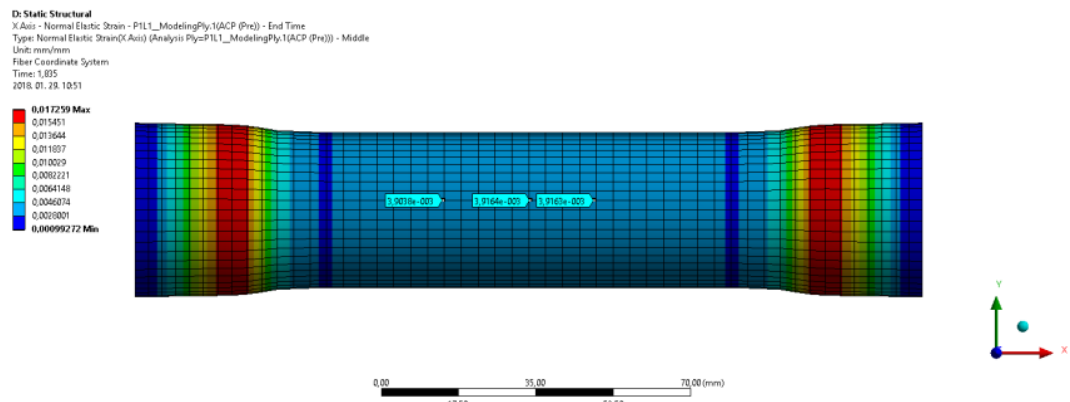

Figure 15. Strain in material direction 1, ply1

Strain in material direction 1 in yarn coordinate system can be observed in Figure 15. These strain values tend to be much lower than strains in material direction 1 due to high modulus of elasticity $\mathrm{E}_{1}$.

Shear strain in plane 12, having the same distribution as strain in material direction 1 has a predominant role in the structural behavior of hose piece under tension because of the load being off-axis to the yarn direction and shear moduli being relatively low. Normal strain in material direction 2, having the same distribution as shear strain in plane 12 , is also considerably significant being the other strain component into which global longitudinal strain is transformed. Strains are almost equally distributed along reinforcement plies.

Stress components of hose piece in material direction 1, material direction 2 and in plane 12 have the same distribution as their strain counterparts. 
Maximum strain and stress results for each reinforcement ply in the middle range of the specimen between grips are presented in Table 3 and Table 4 respectively. Results are listed at a displacement of $30 \mathrm{~mm}$, therefore results can be compared to results at room temperature. Table 3 and 4 also contains results of FE simulation of hose piece at room temperature.

Table 3. Maximum strains in each reinforcement ply in the middle range at $-40^{\circ} \mathrm{C}$ in vertical midplane $Y Z$

\begin{tabular}{|c|c|c|c|c|}
\hline ply no. & $\varepsilon_{x, \max }[-]$ & $\varepsilon_{1, \max }[-]$ & $\boldsymbol{\varepsilon}_{2, \max }[-]$ & $\gamma_{12, \max }[-]$ \\
\hline 1 & 0.2417 & 0.0039 & 0.1251 & -0.3398 \\
& $(0.2423)$ & $(0.0026)$ & $(0.1251)$ & $(-0.3362)$ \\
\hline 2 & 0.242 & 0.0035 & 0.1245 & 0.3356 \\
& $(0.2437)$ & $(0.0018)$ & $(0.1245)$ & $(0.3406)$ \\
\hline 3 & 0.2447 & 0.0026 & 0.1252 & -0.3405 \\
& $(0.2464)$ & $(0.0012)$ & $(0.1254)$ & $(-0.3464)$ \\
\hline 4 & 0.2469 & 0.0029 & 0.1279 & 0.3452 \\
& $(0.2484)$ & $(0.0014)$ & $(0.1261)$ & $(0.3508)$ \\
\hline
\end{tabular}

Table 4 Maximum stresses in each reinforcement ply at $-40^{\circ} \mathrm{C}$ in vertical midplane $Y Z$

\begin{tabular}{|c|c|c|c|c|}
\hline ply no. & $\begin{array}{c}\sigma_{x, \max } \\
{[M P a]}\end{array}$ & $\begin{array}{c}\sigma_{1, \max } \\
{[M P a]}\end{array}$ & $\begin{array}{c}\sigma_{2, \max } \\
{[M P a]}\end{array}$ & $\begin{array}{c}\tau_{12, \max } \\
{[M P a]}\end{array}$ \\
\hline 1 & $13.41(4.93)$ & $7.88(4.38)$ & $7,26(2.32)$ & $-6.38(-2.09)$ \\
\hline 2 & $12.97(4.52)$ & $7.72(3.25)$ & $7,17(2.29)$ & $6.43(2.12)$ \\
\hline 3 & $13.61(3.59)$ & $3.93(0.46)$ & $8,42(2.31)$ & $-6.53(-2.15)$ \\
\hline 4 & $14.62(3.07)$ & $1.98(1.19)$ & $7,38(2.36)$ & $6.62(2.18)$ \\
\hline
\end{tabular}




\section{Uniaxial tension of hose piece at room temperature}

Arrangement of uniaxial tensile test experiment matches arrangement of the tensile test carried out at $-40^{\circ} \mathrm{C}$, moreover, hose piece is $150 \mathrm{~mm}$ long as well.

FE model differs only in the aspect of material properties from the FE model of uniaxial tension at $-40^{\circ} \mathrm{C}$.

Material properties of reinforcement plies at room temperature are as follows: $\mathrm{E}_{1}=1338 \mathrm{MPa}, \mathrm{E}_{2}=\mathrm{E}_{3}=19 \mathrm{MPa}, v_{12}=v_{13}=0.37, v_{23}=0.498 ; \mathrm{G}_{12}=\mathrm{G}_{13}=\mathrm{G}_{23}=6 \mathrm{MPa}$ [13].

Material properties of rubber liners are: $\mathrm{C}_{10}=-0.4982 \mathrm{MPa}, \mathrm{C}_{01}=1.523 \mathrm{MPa}$, $\mathrm{D}=0[1 / \mathrm{MPa}][13]$.

\subsection{Results of uniaxial tensile test experiment and FE simulation at room temperature}

FE simulation and test experiment results at room temperature show good agreement in the entire range of uniaxial tension (Figure 16).

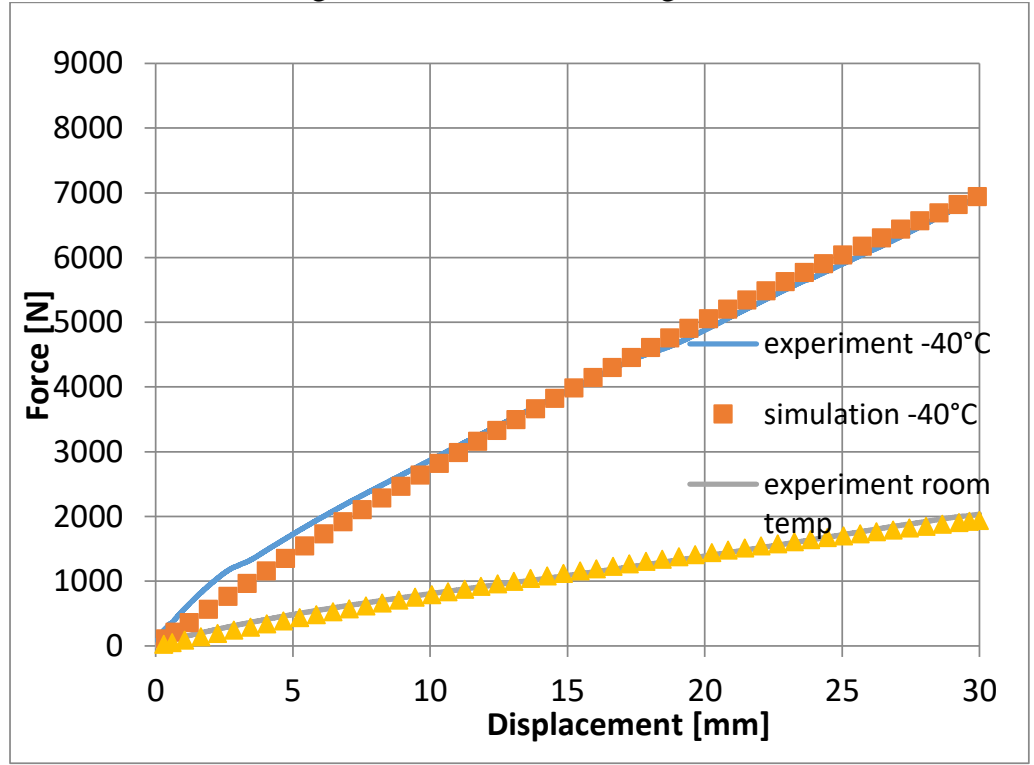

Figure 16. Force displacement curves of hose piece at $-40^{\circ} \mathrm{C}$ and at room temperature 
Proportion of the slope of force-displacement curve of hose piece at $-40{ }^{\circ} \mathrm{C}$ and the slope of force-displacement curve of hose piece at room temperature is 3.4.

Maximum strain and stress results can be seen in Table 3 and Table 4 in brackets. Strain results at $-40^{\circ} \mathrm{C}$ and at room temperature are nearly identical in the case of strain in global X direction $\left(\varepsilon_{\mathrm{x}}\right)$, strain in material direction $2\left(\varepsilon_{2}\right)$ and strain in plane $12\left(\gamma_{12}\right)$. Strain in material direction $1\left(\varepsilon_{1}\right)$, strain at $-40^{\circ} \mathrm{C}$ is twice as much as at room temperature. Stress at $-40^{\circ} \mathrm{C}$, in material direction 1 is 3.6 times, in material direction 2 is 3.3 times, in plane 12 is 3.3 times as much as at room temperature. The higher stresses at $-40^{\circ} \mathrm{C}$ are attributed to the increased modulus of elasticity of rubber, stress components are nearly directly proportional to the modulus of elasticity of rubber.

\section{Conclusions}

Experimental and FE simulation results of standard test specimen and hose piece at $-40^{\circ} \mathrm{C}$ and at room temperature in the entire displacement range are in good agreement with each other.

Strain values of standard test specimen at the point of rupture (displacement of $11.7 \mathrm{~mm}$ ) at $-40^{\circ} \mathrm{C}$ are nearly 0.9 times the strain values arising at the tension of hose piece at $-40^{\circ} \mathrm{C}$ at a displacement of $30 \mathrm{~mm}$. Stress values at $-40^{\circ} \mathrm{C}$ and at room temperature have the same proportion.

Strains arising in material direction 2 and in plane 12 in hose piece at a displacement of $30 \mathrm{~mm}$, at $-40^{\circ} \mathrm{C}$ have the same magnitude as at room temperature. Strain values in material direction 1 , at $-40^{\circ} \mathrm{C}$ are twice as much as values at room temperature. Strain values in material direction 2 and in plane 12 are much higher than strains in material direction 1.

Modulus of elasticity of rubber at $-40^{\circ} \mathrm{C}$ is approximately three times the modulus of elasticity of rubber at room temperature. Stress components in reinforcement plies are approximately 3.3 times as much as those of room temperature on average. Slope of force-displacement curves of hose piece at $-40^{\circ} \mathrm{C}$ is 3.4 times as much as the slope of that at room temperature. It can be stated that a change in moduli of elasticity $\left(E_{2}, E_{3}\right)$ and shear moduli $\left(G_{12}, G_{23}, G_{13}\right)$ is directly proportional to a change in the modulus of elasticity of matrix (being rubber), thus a change in stress components is directly proportional to a change in modulus of elasticity of matrix.

\section{Acknowledgement}

Technical support of Gábor Szebényi at Department of Polymer Engineering, Budapest University of Tecnology and Economics) is highly appreciated. Authors 
would also like to express their gratitude to György Szabó at Department of Machine and Product Design, Budapest University of Technology and Economics for test specimen preparation.

The recent study and publication was realized within the Knorr-Bremse Scholarship Program supported by the Knorr-Bremse Rail Systems Budapest.

\section{References}

[1] C. Kaynak, O. Mat, Uniaxial fatigue behavior of filament-wound glassfiber/epoxy composite tubes, Composites Science and Technology 61 (13) (2001) pp. 1833-1840. doi: $10.1016 / \mathrm{S} 0266-3538(01) 00084-7$

[2] J. H. S.Almeida Jr, M. Ribeiro, T. Volnei, S. C. Amico, Damage modeling for carbon fiber/epoxy filament wound composite tubes under radial compression, Composite Structures 160 (2017) pp. 204-210. doi: 10.1016/j.compstruct.2016.10.036

[3] M. Carroll, F. Ellyin, D. Kujawski, A. S. Chiu, The rate-dependent behaviour of $\pm 55^{\circ}$ filament-wound glass-fibre/epoxy tubes under biaxial loading, Composites Science and Technology 55 (4) (1995) pp. 391-403. doi: 10.1016/0266-3538(95)00119-0

[4] P. D. Soden, R. Kitching, P. C. Tse, Experimental failure stresses for $\pm 55^{\circ}$ filament wound glass fibre reinforced plastic tubes under biaxial loads, Composites, 20 (2) (1989) pp.125-135. doi: 10.1016/0010-4361(89)90640-X

[5] P. Y. Manach, Mechanical behavior of fabric-reinforced elastomer straight flexible hoses, Applied and Computational Mechanics 2 (2008) pp. 291-302.

[6] L. P. Kollár, G. S. Springer, Mechanics of Composite Structures, Cambridge Univ. Press, Cambridge, 2003

[7] P. K. Dutta, Structural Fiber Composite Materials for Cold Regions, Journal of Cold Regions Engineering 2 (3) (1988) pp.124-134. doi: 10.1061/(ASCE)0887-381X(1988)2:3(124)

[8] P. K. Dutta, D. Hui, Low-temperature and freeze-thaw durability of thick composites, Composites Part B: Engineering 27 (3-4) (1996) pp. 371-379. doi: 10.1016/1359-8368(96)00007-8 
[9] P. K. Dutta, Tensile strength of unidirectional fiber composites at low temperatures. Proceedings, Sixth Japan-U.S. Conference on Composite Materials, Technomic Publishing AG, Orlando, 1992, pp. 782-792.

[10] S. Sánchez-Sáez, T. Gómez-del Río, E. Barbero, R. Zaera, C. Navarro, Static behavior of CFRPs at low temperatures, Composites Part B: Engineering 33 (5) (2002) pp. 383-390. doi: $10.1016 / \mathrm{S} 1359-8368(02) 00021-5$

[11] K. K. Chawla, Composite Materials Science and Engineering, 3rd Edition, Springer, New York, London, 2009.

[12] C. C. Chamis, NASA Tech. Memo. 83320, presented at the 38th annual conference of the Society of Plastics Industry (SPI), Houston (1983).

[13] Gy. Szabó, K. Váradi, D. Felhős, Finite Element Model of a Filament-Wound Composite Tube Subjected to Uniaxial Tension, Modern Mechanical Engineering 7 (4) (2017), pp. 91-112. doi: $10.4236 / \mathrm{mme} .2017 .74007$

[14] K. Battermann, R. Köhler, Elastomere Federung - Elastische Lagerungen: Grundlagen ingenieurmässiger Berechnung und Konstruktion, Ernst, Wilhelm \& Sohn, Berlin, 1982.

[15] Ansys Mechanical User's Guide, Engineering Data User's Guide, Material Data, Mechanical Material Curve Fitting

[16] J. Karger-Kocsis, A. Mousa, Z. Major, N. Békési, Dry friction and sliding wear of EPDM rubbers against steel as a function of carbon black content, Wear 264 (3-4) (2008) pp. 359-367. doi: 10.1016/j.wear.2007.03.021 